\title{
Phospholipid Self-assemblies Shaped Like Ancient Chinese Coins for Artificial Organelles
}

\author{
Chao Li, Qingchuan Li, Zhao Wang, Xiaojun Han*
}

State Key Laboratory of Urban Water Resource and Environment School of Chemistry and Chemical Engineering, Harbin Institute of Technology, 92 West Da-Zhi Street, Harbin 150001, China

Email: hanxiaojun@hit.edu.cn

Email: hanxiaojun@hit.edu.cn

\section{Table of Contents}

Lipid compositions of phospholipid assembly systems............................................

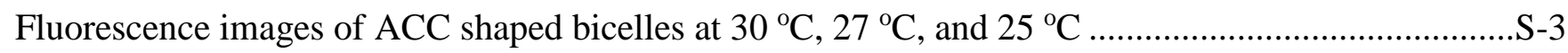

The serial sliced confocal images of one stacked cisterna structure …..................................................S-3

Fluorescence images of stacked cisterna structures encapsulated with RBITC-dextran.........................S-4

Membrane fusion driven by electrostatic interaction ....................................................................... -4

Fluorescence images of artificial organelles with inside cascade enzyme reactions...............................S-5

The control experiments with no GOx, no HRP, and no melittin....................................................... S-5 
Table S1. Lipid compositions of phospholipid assembly systems

\begin{tabular}{|c|c|c|c|}
\hline $\begin{array}{l}\text { Phospholipid assembly } \\
\text { systerms }\end{array}$ & Lipid compositions & $\begin{array}{l}\text { Fluorescence } \\
\text { probes }\end{array}$ & $\begin{array}{l}\text { Probe concen- } \\
\text { tration }\end{array}$ \\
\hline $\begin{array}{l}\text { ACC shaped phospho- } \\
\text { lipid bicelles }\end{array}$ & DPPC $(95 \%)+$ NBD-PE $(5 \%)$ & NBD-PE & $\begin{array}{l}5 \% \text { (mass per- } \\
\text { centage) }\end{array}$ \\
\hline Artificial organelles & $\begin{array}{l}\text { DPPC }(75 \%)+\text { DMPS }(10 \%)+\text { Biotin-PE }(10 \%) \\
+ \text { NBD-PE }(5 \%)\end{array}$ & NBD-PE & $\begin{array}{l}5 \% \text { (mass per- } \\
\text { centage) }\end{array}$ \\
\hline GOx- loaded LUVs & DOPC $(89.5 \%)+$ DOTAP $(10 \%)+$ TR-DHPE $(0.5 \%)$ & TR-DHPE & $\begin{array}{l}0.5 \% \text { (mass } \\
\text { percentage) }\end{array}$ \\
\hline $\begin{array}{l}\text { HRP encapsulated proto- } \\
\text { organelles }\end{array}$ & $\begin{array}{l}\text { DPPC }(75 \%)+\text { DMPS }(10 \%)+\text { Biotin-PE }(10 \%) \\
+ \text { NBD-PE }(5 \%)\end{array}$ & $\begin{array}{l}\text { Rhodamine la- } \\
\text { beled HRP }\end{array}$ & $0.1 \mathrm{U} / \mathrm{mL}$ \\
\hline $\begin{array}{l}\text { RBITC-dextran encap- } \\
\text { sulated proto-organelles }\end{array}$ & $\begin{array}{l}\text { DPPC }(75 \%)+\text { DMPS }(10 \%)+\text { Biotin-PE }(10 \%) \\
+ \text { NBD-PE }(5 \%)\end{array}$ & RBITC-dextran & $200 \mu \mathrm{g} / \mathrm{mL}$ \\
\hline
\end{tabular}

DPPC: 1,2-dipalmitoyl-sn-glycero-3-phosphocholine

NBD-PE: N-(7-nitrobenz-2-oxa-1,3-diazol-4-yl)-1,2-dihexadecanoyl-sn-glycero-3-phosphoethanolamine triethylammonium salt

DMPS: 1,2-dimyristoyl-sn-glycero-3-phospho-Lserine sodium salt

Biotin-PE: 1,2-dipalmitoyl-sn-glycero-3-phosphoethanolamine -N-(cap biotinyl) (sodium salt)

DOPC: 1,2-Dioleoyl-sn-glycero-3-phosphocholine

DOTAP: 1,2-dioleoyl-3-trimethylammonium-propane (chloride salt)

TR-DHPE: 1,2-Dihexadecanol-sn-glycero-3-phosphethanolamine, triethylammonium salt 
(a)

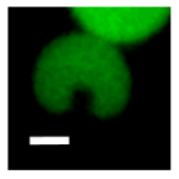

(b)

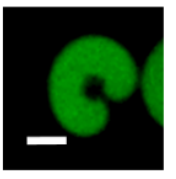

(c)

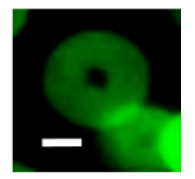

(d)
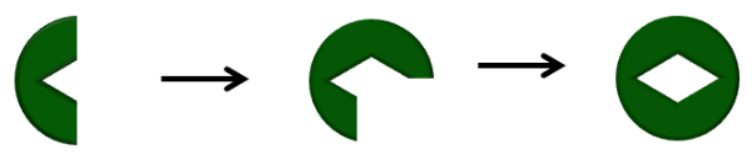

Figure S1. Fluorescence images of ACC shaped phospholipid bicelles at (a) $30^{\circ} \mathrm{C}$, (b) $27^{\circ} \mathrm{C}$, and (c) 25 ${ }^{\circ} \mathrm{C}$ with DPPC concentration of $0.0275 \mathrm{mg} / \mathrm{mL}$ at fixed cooling rate of $1{ }^{\circ} \mathrm{C} / \mathrm{min}$ and ethanol percentage of $48 \%$. (d) Schematic drawing of ACC shaped phospholipid bicelles formation process. The scale bars in (a), (b), and (c) were $5 \mu \mathrm{m}$.
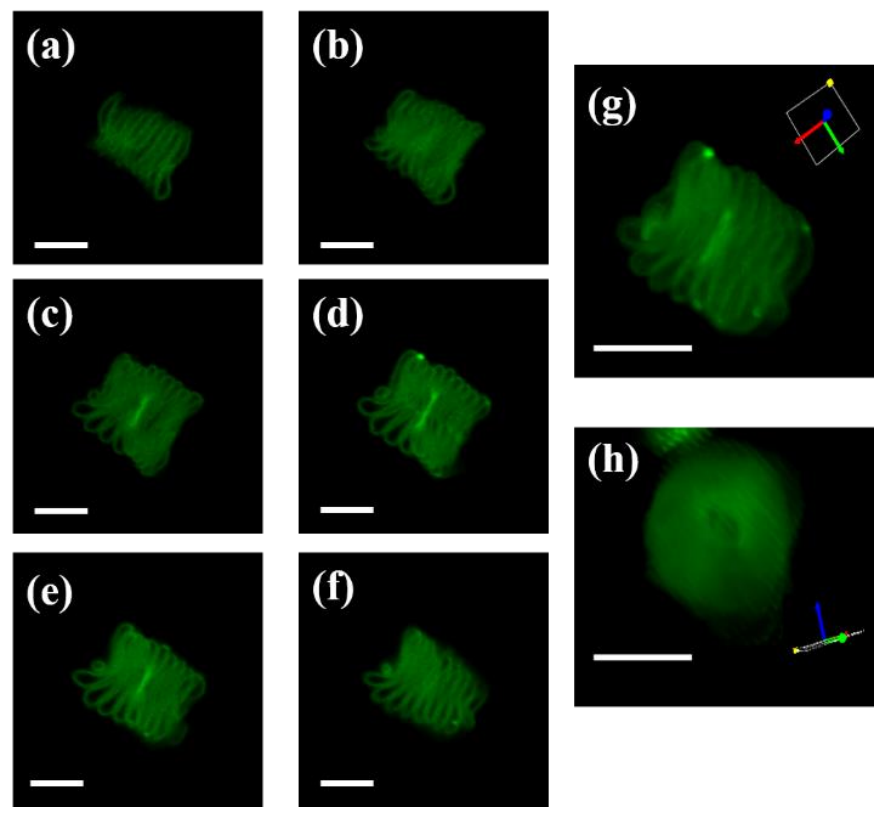

Figure S2. (a)-(f) The serial sliced confocal images of one stacked cisterna structure (artificial organelle) in pure water with $0.82 \mu \mathrm{m}$ interval. (g) Three-dimensional reconstruction of the stacked cisterna structure: (g) side view; (h) top view with a hole in the center. The scale bars were $5 \mu \mathrm{m}$. 

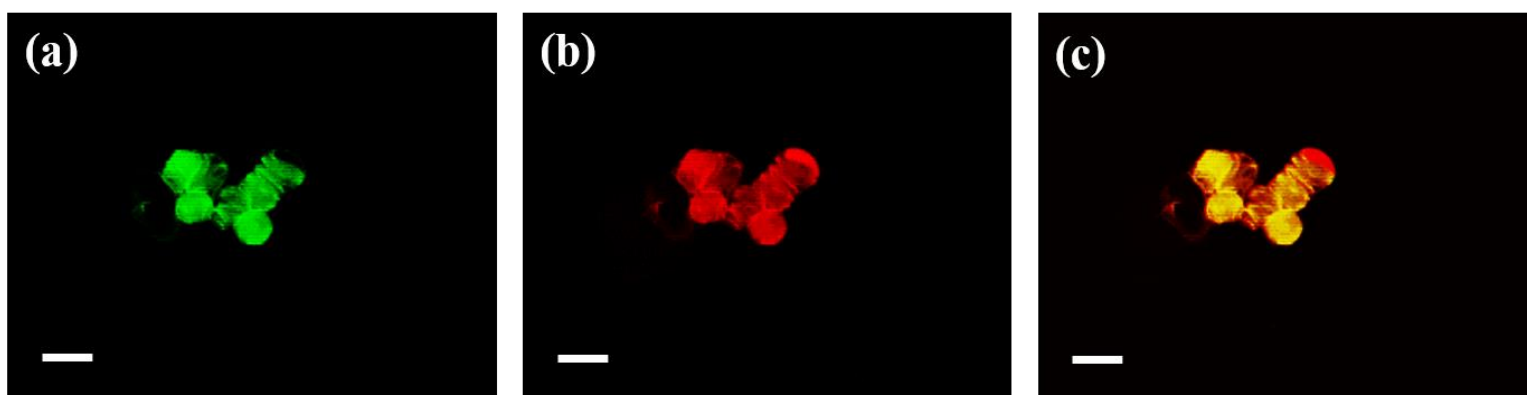

Figure S3. Fluorescence images of stacked cisterna structures encapsulated with RBITC-dextran after adding avidin (20 $\mu \mathrm{g} / \mathrm{mL}$ ): (a) green filter image, (b) red filter image and (c) the merged image of (a) and (b). The scale bars in (a), (b), and (c) were $5 \mu \mathrm{m}$.
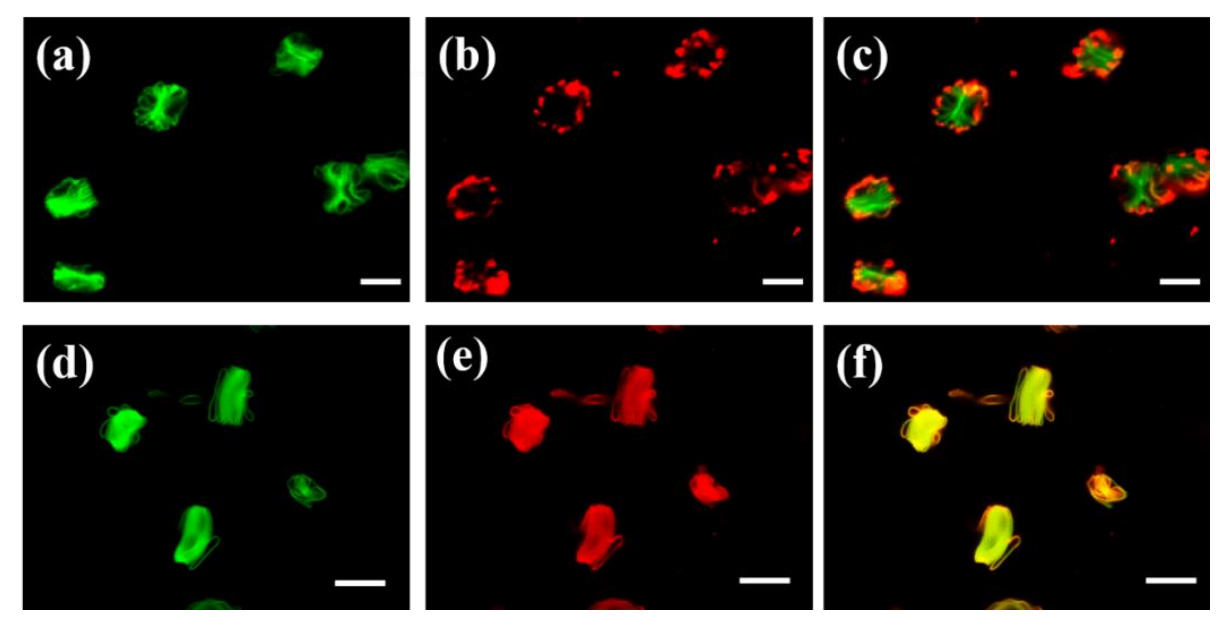

Figure S4. Fluorescence images of positive charge DOPC LUV (containing 10\% DOTAP, 7.5 mV) adsorbed onto the membrane surface of artificial organelles (containing 10\% DMPS, -10.1 mV): (a) the image from green filter, (b) the image from red filter and (c) the merged image of (a) and (b). The TRlabeled positively charged phospholipid vesicles fused with the NBD-labeled negatively charged artificial organelles: (d) the image from green filter, (e) the image from red filter and (f) the merged image of (d) and (e). The scale bars in (a)- (f) were $5 \mu \mathrm{m}$. 

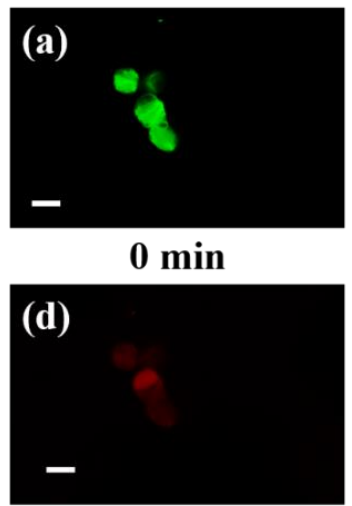

$6 \mathrm{~min}$

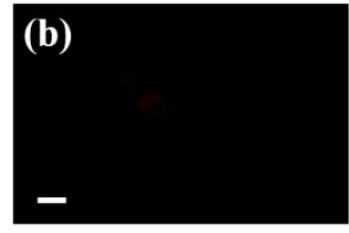

0 min

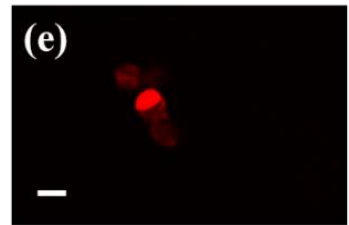

$9 \min$

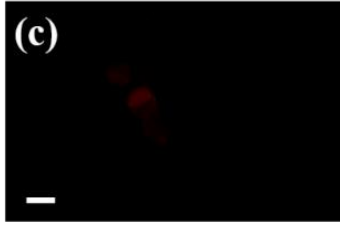

$3 \mathrm{~min}$

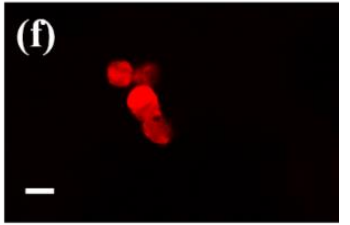

$12 \min$

Figure S5. Fluorescence images of artificial organelles with inside cascade enzyme reactions via membrane fusion as a function of time. (a) The image from green filter at $0 \mathrm{~min}$. (b) - (f) The images from red filter at $0 \mathrm{~min}, 3 \mathrm{~min}, 6 \mathrm{~min}, 9 \mathrm{~min}$, and $12 \mathrm{~min}$, respectively. The scale bars in (a)- (f) were $5 \mu \mathrm{m}$.

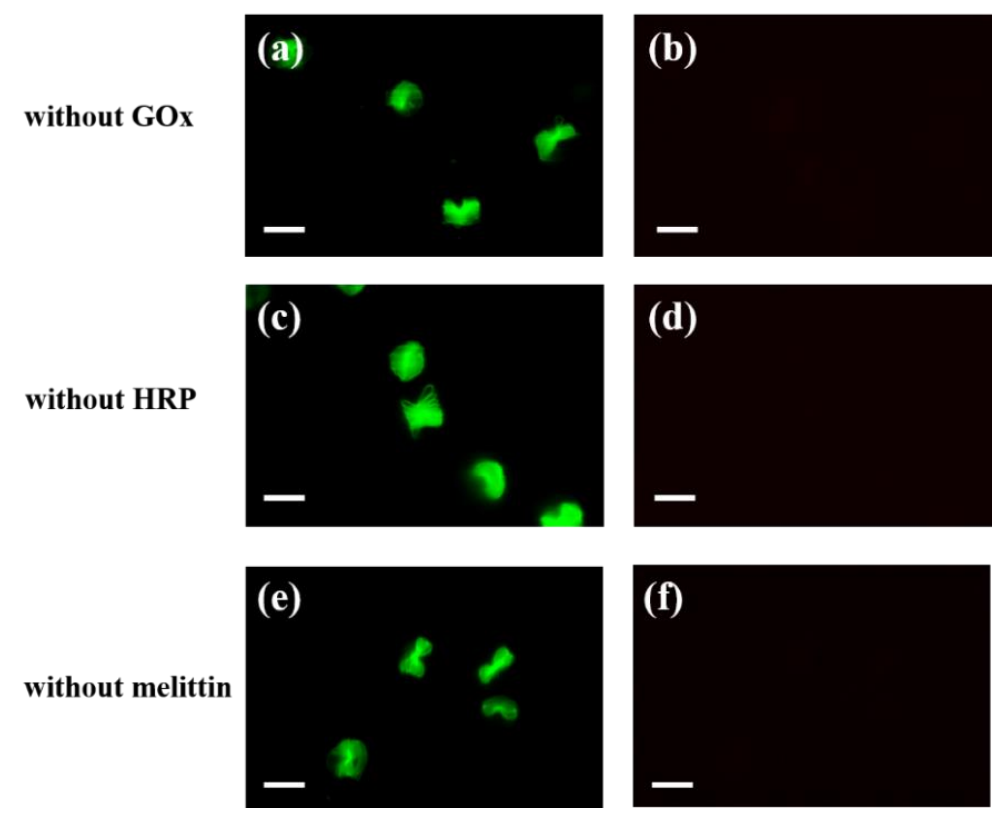

Figure S6. Fluorescence images of the artificial organelles with inside enzyme cascade reactions with no GOx (a), (b), with no HRP (c), (d), and with no melittin (e), (f). Images (a), (c), (e) were taken from green filter, whist images (b), (d), (f) were obtained from red filter. The scale bars in (a)- (f) were $5 \mu \mathrm{m}$. 